\title{
Percutaneous endoscopic gastrostomy placement without sedation in high-risk patients: A safe and well-tolerated technique
}

\author{
(1) Güngör Gül,' 이 Mehmet Akif Aydın² \\ 'Department of General Surgery, Private Goztepe Hospital, İstanbul, Turkey \\ ${ }^{2}$ Department of General Surgery, Altinbas University Faculty of Medicine Bahcelievler Medicalpark Hospital, İstanbul, Turkey
}

\begin{abstract}
Introduction: Percutaneous endoscopic gastrostomy (PEG) is regarded as the standard enteral feeding procedure for patients requiring long-term enteral nutrition. Although it is considered as a safe procedure, PEG may be associated with severe cardiorespiratory complications, especially in patients with sedation-induced respiratory compromise. This article is a retrospective analysis of 49 patients at high-risk of complications, who undergone unsedated peroral PEG tube placement.
\end{abstract}

Materials and Methods: PEG was placed in 49 patients through the peroral endoscopic way without sedation. The patients were given pharyngeal anesthesia and the PEG tubes were inserted using the 'pull ' technique. The comorbidities, PEG indications, pharyngeal anesthesia indications, arterial oxygen saturations throughout the procedure, the comfort and the tolerability score and complications were recorded.

Results: Of all patients 27 (55.1\%) were female and 22 (44.9\%) were male. The mean age of the patients was 81 (range: 33-99) years. PEG procedure was performed due to the loss of swallowing reflex and dysphagia in 24 (48.9\%), replacement of the previously inserted PEG tube in 11 (22.5\%), malnutrition in 9 (18.3\%) and nasogastric tube intolerance in $5(10.2 \%)$ patients. Unsedated procedure was performed due to aspiration pneumonia in 21 (42.8\%), chronic pulmonary disease in $10(20.4 \%)$, request from patient relatives in 15 (30.6\%), and on patient's own request in 3 (6.1\%). Modified Gloucester Comfort Scale was used to evaluate the comfort and the tolerability of the patients. According to the scale, $24.4 \%$ of the patients showed no signs of discomfort, $42.8 \%$ showed mild signs of discomfort yet well tolerated the procedure. Only $8.1 \%$ showed significant discomfort. As complications, tube dislodgement was observed in 3 patients and wound infections were recorded in 4 patients.

Conclusion: PEG placement using a peroral route without sedation is a safe and well-tolerated method in patients with high sedation risk.

Keywords: Percutaneous endoscopic gastrostomy; pharyngeal anesthesia; sedation.

\section{Introduction}

Meeting metabolic needs of patients with restricted oral intake is always encountered as an important problem. Enteral nutrition is preferred especially in mid-term and long-term feeding in meeting this demand because of its advantages including lower cost compared to parenteral nutrition, lower risk of complications associated with intravenous route, its stimulating effect on gastrointesti- 
nal route and prevention of bacteremia due to bacterial translocation. ${ }^{[1,2]}$

The gastrointestinal system should be functional for enteral nutrition.It is possible to meet nutritional needs with nasoenteral tubes in patients of which their oral intake is likely to be inadequate for a period shorter than one month. However, tube gastrostomy and tube enterostomy should be preferred in long-term feding which can be described as a period exceeding 4 weeks. Nutrition with tube gastrostomy is the most commonly used method. In this method, insertion of the tube is possible with surgical (laparotomy or laparoscopy), endoscopic or radiologic techniques. ${ }^{[3]}$

Percutaneous endoscopic gastrostomy (PEG) is considered to be the most preferred method. This method has some advantages such as being less invasive compared to the surgical method, not requiring general anesthesia and lower cost. ${ }^{[4]}$ In a study comparing surgical method and endoscopic method in terms of morbidity and mortality, no significant difference was found between the two methods. ${ }^{[5]}$

PEG method was described for the first time by Gauderer et al. ${ }^{[6]}$ in 1980 by performing in 12 pediatric and 19 adult patients.

Patients with diseases impairing middle and long term oral intake such as cerebrovascular diseases, dementia, Parkinson's disease, head \& neck tumors, head traumas and upper gastrointestinal system cancers are appropriate candidates for PEG. ${ }^{[7]}$

PEG procedure mostly requires sedation. However, the majority of patients who need PEG have comorbidities which increase the risk of sedation. PEG procedure may be delayed and even cancelled due to these reasons. ${ }^{[8]}$

In a study from England, mortality was reported to occur due to respiratory tract diseases within the first 30 days of the follow-up in $70 \%$ of patients undergoing PEG. ${ }^{[9]}$
In our study, we aimed to share our results of unsedated PEG applications performed in two centers.

\section{Materials and Methods}

\section{Patients}

Medical records and files of a total of 49 patients who underwent PEG placement using peroral endoscopy with pharyngeal anesthesia without sedation at the general surgery endoscopic units of Private Göztepe Hospital and Altınbas University Faculty of Medicine Medical Bahcelievler Hospital between March 2014 and December 2019 were retrospectively evaluated.

Patients' demographic features, PEG indications, comorbidities, reasons for pharyngeal anesthesia, oxygen saturations during the procedure, and complications were retrospectively screened from the patient files and data were collected. In addition, data of evaluations of patient comfort including compliance and tolerance during the procedure that were recorded by the endoscopy nurse using the Modified Gloucester Comfort Scale ${ }^{[10]}$ were collected and examined. Discomfort can be described as severe belching, retching, coughing and non-compliance. No discomfort sign was evaluated as 1 point on the scale, on the other hand extreme discomfort during the procedure is referred as 5 points (Table 1).

Before the procedure, patients and/or relatives were verbally informed by the physician about the procedure and written consent was then obtained from the patients who were capable and from the relatives of the patients who were not capable.

\section{Procedure}

All patients were administered intravenous Cezol $1 \mathrm{~g}$ (Deva Holding, Istanbul, Turkey) 30 minutes before the procedure for prophylaxis. Lidocaine 10\% (Vem İlaç, Ankara, Turkey) was sprayed 5 times for pharyngeal anesthesia in

\section{Table 1. Modified Gloucester comfort scale}

\begin{tabular}{lcl} 
Score & Scale & Descripton \\
\hline 1 & No & No discomfort-resting comfortably throughout \\
2 & Minimal & One or two episodes of mild discomfort,well tolerated \\
3 & Mild & More than two episodes of discomfort,adequately tolerated \\
4 & Moderate & Significant discomfort, experienced several times during the procedure \\
5 & Severe & Extreme discomfort, experienced frequently during the procedure
\end{tabular}


patients admitted to the endoscopy unit. The procedure was performed in the supine position and the patients were intubated with a gastroscope (diameter: $9.8 \mathrm{~mm}$, length: $103 \mathrm{~cm}$, Fujinon 2500, Tokyo, Japan) via oral route. In addition to the basic diagnostic endoscopy, after the passage patency was assessed, an appropriate site where the tube will be placed was determined by transillumination and finger indentation. After cleaning the area with poviiodeks antiseptic solution (Kimpa İlaç, İstanbul, Turkey) the local anesthetic agent, 2\% prilocaine hydrochloride (Vem Ilac, Ankara, Turkey) was superficially applied on the site of the tube insertion and vertically along the tube trace. PEG tube (Safety PEG KitTM, Boston Scientific Co., Natick MA, USA) was inserted with the pull technique. Pulse and oxygen saturation were monitored with pulse oximetry during the procedure. No analgesic agent was given to the patients during and after the procedure.

\section{Statistical Analysis}

Since the study has a descriptive design, continuous variables were expressed with mean, standard deviation, median, minimum and maximum values, while categorical variables were defined with frequency (n) and percentage (\%).

The statistical analysis was performed utilizing MedCalc Statistical Software version 12.7.7 (MedCalc Software bvba, Ostend, Belgium; http://www.medcalc.org 2013) software.

\section{Results}

PEG procedures were successfully performed with pharyngeal anesthesia without sedation in a total of 49 patients in two centers. Of all patients 27 (55.1\%) were female and $22(44.9 \%)$ were male. The median age of the patients was 81 (33-99) years. When comorbidities were evaluated; hypertension was found in 17 (34.7\%), diabetes mellitus in 16 (32.7\%), coronary artery disease in 13 (26.5\%9, chronic obstructive pulmonary disease in $6(12.2 \%)$ and cardiac arrhythmias in 4 (8.2\%) patients. Demographic data and comorbidities of the patients were summarized in Table 2.

When PEG indications were evaluated; loss of swallowing reflex and dysphagia secondary to neurologic diseases were found in 24 (48.9\%) patients, replacement of PEG tube due to perforation or dislodgement in 11 (22.5\%) patients, malnutrition in $9(18.3 \%)$ patients and nasogastric tube intolerance in $5(10.2 \%)$ patients (Table 3$).$

When the reasons for preferring unsedated pharyngeal anesthesia were examined; aspiration pneumonia was
Table 2. Patient demographic data and comorbidity

Mean Med (min-max)

$\begin{array}{lcc}\text { Age (year) } & \begin{array}{c}79.9 \pm 12.7 \\ \text { n }\end{array} & \begin{array}{c}81(33-99) \\ \%\end{array} \\ & \text { n } & \\ \text { Gender } & & 55.1 \\ \quad \text { Female } & 27 & 44.9 \\ \quad \text { Male } & 22 & \\ \text { Comorbidity } & & 32.7 \\ \quad \text { Diabetes mellitus } & 16 & 26.5 \\ \text { Coronary artery diseas } & 13 & 8.2 \\ \text { Cardiac arrythmia } & 4 & 34.7 \\ \text { Hypertension } & 17 & 12.2 \\ \text { COPD } & 6 & 8.2 \\ \text { Other (kyphosis, bipolar } & 4 & \\ \text { diseas, multiple sclerosis) } & & \end{array}$

SD: Standart deviation; COPD: Chronic obstructive pulmonary disease.

Table 3. Percutaneous endoscopic gastrostomy endications

\begin{tabular}{lcc} 
& n & $\%$ \\
\hline Dysphagia & 14 & 28.5 \\
PEG replacement & 11 & 22.5 \\
Loss of swallowing reflex & 10 & 20.4 \\
Malnutrition & 9 & 18.3 \\
NGT intolerance & 5 & 10.2 \\
Total & 49 & 100.0 \\
\hline NGT: Nasogastric tube. & & \\
\hline
\end{tabular}

found in $21(42.8 \%)$ patients and respiratory failure due to chronic pulmonary disease in 10 (20.4\%) patients. PEG procedure was performed without sedation on the request of patient relatives in $15(30.6 \%)$ patients and on patient's own request in $3(6.1 \%)$ patients (Table 4 ).

Table 4. Pharyngeal Anesthesia indications

\begin{tabular}{lcc} 
& n & $\%$ \\
\hline Aspiration pneumonia & 21 & 40.8 \\
Family members' decision & 15 & 30.6 \\
Chronic respiratory diseases & 10 & 20.4 \\
Patient decision & 3 & 6.1 \\
Total & 49 & 100.0 \\
\hline
\end{tabular}


According to the Modified Gloucester Comfort Scale performed to evaluate patient comfort during the procedure; it was observed that $12(24.4 \%)$ patients felt no discomfort at all, $21(42.8 \%)$ patients well-tolerated the procedure except for 1-2 mild discomfort during the entire procedure, 12 (24.4\%) patients experienced more than 2 discomfort attacks, yet did not interfere with the flow of the procedure. On the other hand, marked discomfort was encountered for many times during the procedure in $3(6.1 \%)$ patients and extreme discomfort was observed during the procedure only in one patient. In addition, oxygen saturations were maintained at acceptable levels in all procedures (the median oxygen saturation: 92\% [range: 87-98\%]) (Table 5).

No direct endoscopy related complication was observed in any patient. Tube dislodgement was observed in 3 patients within the first month, and these tubes were replaced via the same tract. Four patients developed wound site infections and were recovered with wound site care and appropriate antibiotherapy administered according to the cultures.

\section{Discussion}

Endoscopic insertion of the endoscopic gastrostomy tube under sedation may be contraindicated in some patients and is a high-risk procedure especially in patients with serious respiratory diseases. In such cases the procedure can be carried out without sedation as an alternative. However unsedated endoscopic procedures may trigger anxiety,embarrassment and discomfort such as retching, gagging and pain.

Table 5. Patient Comfort Score (Modified Gloucester Scale) and Minimum $\mathrm{SPo}_{2}$ during the procedure

\begin{tabular}{|c|c|c|}
\hline Modified gloucester scale & $\mathbf{n}$ & $\%$ \\
\hline 1 & 12 & 24.4 \\
\hline 2 & 21 & 42.8 \\
\hline 3 & 12 & 24.4 \\
\hline 4 & 3 & 6.1 \\
\hline 5 & 1 & 2 \\
\hline Total & 49 & 100 \\
\hline \multirow[t]{2}{*}{$\begin{array}{l}\text { Minimum } \mathrm{SPo}_{2} \text { during } \\
\text { procedure }\end{array}$} & Mean & Med (min-max) \\
\hline & $1.6+/-2.4$ & $92(87-98)$ \\
\hline
\end{tabular}

In 2012, Steed et al. ${ }^{[8]}$ reported in a small group of 10 patients for the first time that PEG can be applied with pharyngeal topical anesthesia in patients who can not receive sedation due to comorbidity. Sedation application causes respiratory arrest or worsening of respiratory functions especially due to comorbidity and especially respiratory dysfunction in patients with an indication for PEG. ${ }^{[1]]}$

It is possible to perform transnasal unsedated PEG using a small-diameter endoscopy in order to avoid sedation complications, but there may be an increased risk for failure due to inability to pass through the nasal cavity, for epistaxis and peristomal infections because of nasomucosal injury. ${ }^{[12-15]}$

Lian-Feng Lin et al. ${ }^{[16]}$ reported that no complication was observed in patients who underwent unsedated transnasal percutaneous endoscopic gastrostomy except for epistaxis and minor wound infection and the procedure is a reliable alternative which is more easily tolerated.

In another study, unsedated PEG technique was reported to be well-tolerated by $68.3 \%$ of the patients and no discomfort sign was observed during the procedure. No documented complication was found in the remaining patient group during the procedure. ${ }^{[17]}$

In our study, comfort of the patients during the procedure was recorded by the endoscopy nurse using the Modified Gloucester Comfort Scale and no discomfort or minimal discomfort was observed in $67.2 \%(n=33)$ of the patients.

In a comparative study by Watanabe et al., ${ }^{[18]}$ transoral application was reported to be more successful in terms of the rate of applicability, procedure time, comfort during the procedure and complications in patients who underwent transoral and transnasal PEG using a small-caliber endoscope.

In a study comparing PEG procedures performed with Ultrathin and conventional endoscopy without sedation and with conventional endoscope with sedation, no statistically significant difference was found in terms of $\mathrm{SaO}_{2}$ and mean blood pressure, and minor complications such as apnea-hyperventilation, aspiration pneumonia and elevated blood pressure were found to be lower in the group with ultrathin endoscopy performed without sedation. ${ }^{[19]}$

In a clinical review by SP et al., ${ }^{[20]}$ investigating complications associated with percutaneous endoscopic gastrostomy (PEG), transient hypoxia was underlined to be a commonly encountered complication in PEG procedure 
performed with sedation. In our study, since sedation carries high risks, the procedures were performed with pharyngeal anesthesia and via peroral route without sedation in patients in whom PEG was postponed or could not be performed, and no significant decrease was recorded in oxygen saturation during the procedures.

Alternatively, the Percutaneous Radiologic Gastrostomy (PRG) method can be used. There are studies reporting that this method is a safe and effective technique. ${ }^{[21,22]}$ However, this method is not commonly preferred, because of some disadvantages such as requiring a specialist interventional radiologist, the risk of occlusion because of the smaller calibration of the tubes used, technical problems requiring re-insertion in most $(40 \%)$ placed tubes. In a study comparing PEG and PRG, mortality, peritonitis and surgical site infections were reported to be lower. ${ }^{[23]}$

The limitations of this study are that we certainly beleive that although the results that we obtained from this study seem encouraging, nevertheless studies with larger groups of patients would probably provide more reliable information.

\section{Conclusion}

Percutaneous endsocopic gastrostomy procedure appears to be the most appropriate method for patients with limited or no oral intake. In this study we aimed to demonstrate that this procedure can be carried out without sedation safely and effectively especially in patients at risk for sedation.

\section{Disclosures}

Ethichs Committee Approval: Retrospective study.

Peer-review: Externally peer-reviewed.

Conflict of Interest: None declared.

Authorship Contributions: Concept - G.G., M.A.A.; Design - G.G., M.A.A.; Supervision - G.G., M.A.A.; Materials - G.G., M.A.A.; Data collection and/or processing - G.G., M.A.A.; Analysis and/or interpretation - G.G., M.A.A.; Literature search - G.G., M.A.A.; Writing - G.G., M.A.A.; Critical review - G.G., M.A.A.

\section{References}

1. Alverdy J, Chi HS, Sheldon GF. The effect of parenteral nutrition on gastrointestinal immunity. The importance of enteral stimulation. Ann Surg 1985;202:681-4. [CrossRef]

2. Deitch EA, Ma WJ, Ma L, Berg RD, Specian RD. Protein malnu- trition predisposes to inflammatory-induced gut-origin septic states. Ann Surg 1990;211:560-7. [CrossRef]

3. Hucl T, Spicak J. Complications of percutaneous endoscopic gastrostomy. Best Pract Res Clin Gastroenterol 2016;30:769-81. [CrossRef]

4. Rahnemai-Azar AA, Rahnemaiazar AA, Naghshizadian $R$, Kurtz A, Farkas DT. Percutaneous endoscopic gastrostomy: indications, technique, complications and management. World J Gastroenterol 2014;20:7739-51. [CrossRef]

5. Stiegmann GV, Goff JS, Silas D, Pearlman N, Sun J, Norton L. Endoscopic versus operative gastrostomy: final results of a prospective randomized trial. Gastrointest Endosc 1990;36:1-5. [CrossRef]

6. Gauderer MW, Ponsky JL, Izant RJ Jr. Gastrostomy without laparotomy: a percutaneous endoscopic technique. J Pediatr Surg 1980;15:872-5. [CrossRef]

7. Erdogan A. Single endoscopist-performed percutaneous endoscopic gastrostomy tube placement. World J Gastroenterol 2013;19:4172-6. [CrossRef]

8. Steed H, Barrett D, Emm C, Lycett W, O'Toole S, Evans K, et al. Unsedated percutaneous endoscopic gastrostomy insertion: a safe, effective, and well-tolerated method. JPEN J Parenter Enteral Nutr 2012;36:231-4. [CrossRef]

9. Johnston SD, Tham TC, Mason M. Death after PEG: results of the National Confidential Enquiry into Patient Outcome and Death. Gastrointest Endosc 2008;68:223-7. [CrossRef]

10. Ball AJ, Rees CJ, Corfe BM, Riley SA. Sedation practice and comfort during colonoscopy: lessons learnt from a national screening programme. Eur J Gastroenterol Hepatol 2015;27:741-6. [CrossRef]

11. Wollman B, D'Agostino HB. Percutaneous radiologic and endoscopic gastrostomy: a 3-year institutional analysis of procedure performance. AJR Am J Roentgenol 1997;169:15513. [CrossRef]

12. Dumortier J, Lapalus MG, Pereira A, Lagarrigue JP, Chavaillon A, Ponchon T. Unsedated transnasal PEG placement. Gastrointest Endosc 2004;59:54-7. [CrossRef]

13. Vitale MA, Villotti G, D'Alba L, De Cesare MA, Frontespezi S, lacopini $\mathrm{G}$. Unsedated transnasal percutaneous endoscopic gastrostomy placement in selected patients. Endoscopy 2005;37:48-51. [CrossRef]

14. Dumortier J, Napoleon B, Hedelius F, Pellissier PE, Leprince E, Pujol B, et al. Unsedated transnasal EGD in daily practice: results with 1100 consecutive patients. Gastrointest Endosc 2003;57:198-204. [CrossRef]

15. Trevisani L, Cifalà V, Sartori S, Gilli G, Matarese G, Abbasciano $\mathrm{V}$. Unsedated ultrathin upper endoscopy is better than conventional endoscopy in routine outpatient gastroenterology practice: a randomized trial. World J Gastroenterol 2007;13:906-11. [CrossRef]

16. Lin LF, Shen HC. Unsedated transnasal percutaneous endoscopic gastrostomy carried out by a single physician. Dig Endosc 2013;25:130-5. [CrossRef]

17. McCulloch A, Roy O, Massey D, Hedges R, Skerratt S, Wilson $\mathrm{N}$, et al. Nasal unsedated seated percutaneous endoscopic 
gastrostomy (nuPEG): a safe and effective technique for percutaneous endoscopic gastrostomy placement in high-risk candidates. Frontline Gastroenterol 2018;9:105-9. [CrossRef]

18. Watanabe H, Watanabe N, Ogura R, Nishino N, Saifuku Y, Hitomi $\mathrm{G}$, et al. A randomized prospective trial comparing unsedated endoscopy via transnasal and transoral routes using 5.5-mm video endoscopy. Dig Dis Sci 2009;54:2155-60.

19. Sato Y, Goshi S, Kawauchi Y, Nishigaki Y, Mizuno KI, Hashimoto $S$, et al. Safety of unsedated PEG placement using transoral ultrathin endoscopy in patients with amyotrophic lateral sclerosis. Nutr Neurosci 2017;20:71-5. [CrossRef]

20. Schrag SP, Sharma R, Jaik NP, Seamon MJ, Lukaszczyk JJ, Martin ND, et al. Complications related to percutaneous endoscopic gastrostomy (PEG) tubes. A comprehensive clinical review. J Gastrointestin Liver Dis 2007;16:407-18.

21. Chiò A, Galletti R, Finocchiaro $C$, Righi D, Ruffino MA, Calvo $A$, et al. Percutaneous radiological gastrostomy: a safe and effective method of nutritional tube placement in advanced ALS. J Neurol Neurosurg Psychiatry 2004;75:645-7. [CrossRef]

22. Park JH, Kang SW, Won JY, Uhm CW. Fluoroscopy-guided percutaneous gastrostomy with pull technique for the amyotrophic lateral sclerosis patients with very low vital capacity. JPEN J Parenter Enteral Nutr 2010;34:421-5. [CrossRef]

23. Silas AM, Pearce LF, Lestina LS, Grove MR, Tosteson A, Manganiello WD, et al. Percutaneous radiologic gastrostomy versus percutaneous endoscopic gastrostomy: a comparison of indications, complications and outcomes in 370 patients. Eur J Radiol 2005;56:84-90. [CrossRef] 